\title{
UMA LEITURA GEOGRÁFICA DOS PAPÉIS E SIGNIFICADOS DE CIDADES PEQUENAS NA REGIÃO METROPOLITANA DE CAMPINAS-SP
}

\section{Orlando Moreira Junior ${ }^{1}$}

Resumo: A questão central que orientou este trabalho foi analisar os papéis e significados de cidades pequenas numa área metropolitana, tendo como referencial empírico a Região Metropolitana de Campinas-SP. Foram avaliados seis aspectos que possibilitaram a identificação de particularidades na caracterização das cidades pequenas ante o contexto regional metropolitano: as novas e velhas interações com o rural; as cidades pequenas com forte vigor industrial; os centros especializados; as cidades-dormitório; as relações mais próximas de sociabilidade; e o papel do poder local ante a governança regional.

Palavras-chave: Cidades Pequenas; Região Metropolitana; Papéis Urbanos.

\section{READING PAPERS OF GEOGRAPHICAL AND MEANINGS OF SMALL TOWNS IN METROPOLITAN REGION CAMPINAS-SP}

\begin{abstract}
The central question that guided this study was to analyze the roles and meanings of small towns in a metropolitan area, as an empirical reference the Metropolitan Region of Campinas-SP. Six aspects that enable the identification of particulars in the characterization of small towns before the metropolitan regional context were evaluated: the old and new interactions with the rural; small towns with high industrial development; specialized centers; the dormitory towns; the closest relations of sociability; and the role of local government in the face of regional governance.
\end{abstract}

Key words: Small Towns; Metropolitan Region; Urban Roles.

\section{INTRODUÇÃO}

A delimitação de cidade pequena deve superar os critérios quantitativos - especialmente, os de caráter demográfico, devendo considerar, sobretudo, aspectos qualitativos, como por exemplo, as funções exercidas na rede urbana e a diversificação econômica (oferta de produtos, serviços, espetáculos, etc.). Estes abrangem os papéis que as cidades desempenham no contexto regional, as características das funções e atividades desenvolvidas, bem como a dinâmica que envolve o processo de (re) produção espacial.

1. Doutor em Geografia. Professor do curso de Geografia da Universidade Estadual de mato Grosso do SulUEMS (orlandomoreirajr@uems.br). 
Diversos trabalhos acadêmicos tem procurado identificar a natureza e o significado dos papéis urbanos assumidos por cidades pequenas em diferentes recortes territoriais. Sob diversas abordagens e perspectivas, pesquisadores vem elaborando análises a partir da rede urbana, para compreender os processos ligados à economia, à urbanização, à divisão territorial do trabalho e aos aspectos funcionais, principalmente.

Bernardelli (2002, 2003, 2004); Engel et al. (2002); Endlich (2002, 2006, 2009); Engel e Soares (2004); Leão e Sposito (2006); Pinto (2007); Bernardelli e Matushima (2008); Castilho e Chaveiro (2008); Melo (2008); Capel (2009); Casaril (2010); Chagas (2010); Almeida (2010); Spolaor (2010) são alguns exemplos de contribuições que discutem os papéis e as redefinições das funções urbanas a partir de uma análise da rede urbana. Embora tratem de estudos pontuais, uma vez que abrangem diferentes e diversos recortes regionais brasileiros, os pesquisadores citados têm contribuído para identificar aspectos da natureza e das especificidades tanto do papel das cidades pequenas quanto da rede urbana brasileira.

No geral, os papéis desempenhados pelas cidades pequenas estão, intrinsecamente, ligados ao mundo agrícola, mesmo com mudanças significativas que recaíram sobre as atividades produtivas do campo. As alterações na produção agropecuária são implicações de um mercado mundial que, cada vez mais, extrapola a escala local, sucumbindo a tese de cidades pequenas enquanto cidades locais, uma vez que por conta disto "se negam como tais, enquanto pequenas cidades baseadas em processos majoritariamente locais" (DAMIANI, 2006, p. 146).

Os resultados das pesquisas revelam que as relações estabelecidas entre a cidade e o campo assumem relevância expressiva, especialmente, no que concernem as atividades econômicas. Em geral e de modo diferenciado, a base econômica está centrada nas atividades agrícolas ou agroindustriais que se expressam, também, na própria configuração do espaço urbano. De tal modo, os papéis e significados das cidades pequenas possuem uma relação indissociável da tríade rural-urbano-agrícola, que são fundamentais para a sua leitura espacial.

A maior parte das pesquisas que versam sobre o tema das cidades pequenas tem privilegiado o estudo em áreas não metropolitanas ou distantes de grandes centros econômicos. Assim, este ensaio procura contribuir com o estudo delas, seus papéis e 
significados, numa região metropolitana. O objetivo central é identificar características particulares para as cidades pequenas ante um cenário economicamente dinâmico e com aspectos espaciais decorrentes do processo de metropolização.

O referencial empírico deste ensaio é a Região Metropolitana de Campinas, localizada no estado de São Paulo. Composta por 19 municípios ${ }^{2}$, numa área de $3.647 \mathrm{~km}^{2}$, é formada, além da cidade central, por um conjunto de núcleos urbanos de porte médio e pequeno, como está registrado na Tabela 1 e representado na Figura 1.

\begin{tabular}{|l|c|c|c|}
\hline MUNICÍPIOS & POPULAÇÃO (2010) & MUNICÍPIOS & POPULAÇÃO (2010) \\
\hline Holambra & 11.292 & Paulínia & 82.150 \\
\hline Engenheiro Coelho & 15.719 & Itatiba & 101.450 \\
\hline Sto. Antônio de Posse & 20.635 & Valinhos & 106.968 \\
\hline Pedreira & 41.549 & Santa Bárbara d'Oeste & 180.148 \\
\hline Artur Nogueira & 44.220 & Hortolândia & 192.225 \\
\hline Jaguariúna & 44.331 & Indaiatuba & 201.848 \\
\hline Monte Mor & 48.971 & Americana & 210.701 \\
\hline Nova Odessa & 51.278 & Sumaré & 241.437 \\
\hline Cosmópolis & 58.821 & Campinas & 1.080 .999 \\
\hline Vinhedo & 63.685 & Região Metropolitana & 2.798 .427 \\
\hline
\end{tabular}

Tabela 1: População total dos municípios da Região Metropolitana de Campinas, em 2010. Fonte: Censo demográfico de 2010 - IBGE.

Org.: Orlando Moreira Junior (2014).

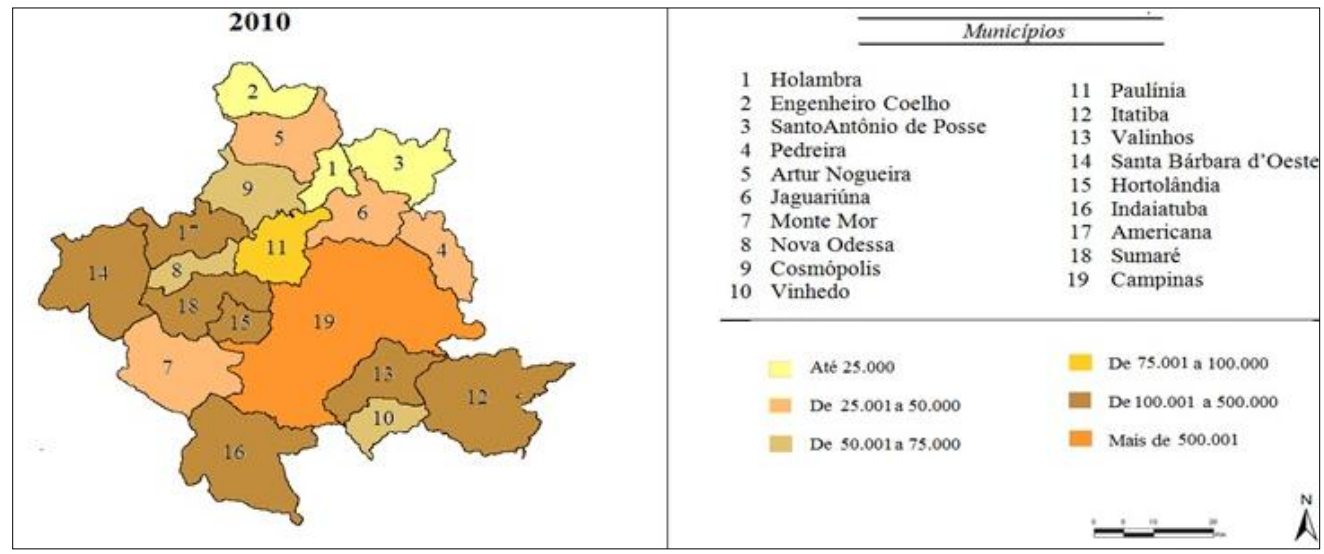

Figura 1: Região Metropolitana de Campinas, por classe de tamanho populacional, em 2010. Org.: Orlando Moreira Junior, 2014.

Para delimitar as cidades que podem ser consideradas pequenas, são apreciados os aspectos populacionais, funcionais e espaciais. De tal modo, têm-se: Holambra, Engenheiro Coelho, Santo Antônio de Posse, Pedreira, Artur Nogueira, Jaguariúna e Monte Mor.

2. O presente trabalho não inclui o município de Morungaba, com 11.775 habitantes, que em março de 2014 passou a ser a vigésima cidade a compor a Região Metropolitana de Campinas.. 
Diante do conjunto de cidades que contemplou o objeto de estudo, puderam ser identificadas seis características mais marcantes que indicam particularidades na leitura espacial de cidades pequenas em áreas metropolitanas: as novas e velhas interações com o rural; as cidades pequenas com forte vigor industrial; os centros especializados; as cidadesdormitório; as relações mais próximas de sociabilidade; e o papel do poder local ante a governança regional.

\section{MATERIA E MÉTODOS}

Para atingir os objetivos e atingir o resultado de identificar as seis características para as cidades pequenas numa região metropolitana, um conjunto de procedimentos teóricos e práticos - uso de técnicas e instrumentos - foi tomado.

O uso de técnicas abrangeu exercícios analítico-práticos que podem ser divididos em quatro etapas:

I. Levantamento bibliográfico em livros, periódicos, teses e dissertações, a partir de palavras-chave, como cidades pequenas, região metropolitana, papéis urbanos, cidades locais, urbano e rural;

II. Coleta de dados secundários no IBGE, AGEMCAMP, EMTU, IPEA, entre outras;

III. Trabalhos em campo para efetuar observações orientadas por meio de um roteiro que tinha como finalidades facilitar o registro dos elementos e das situações particulares que fossem importantes de serem levantadas como informações acerca das características econômicas e socioespaciais das cidades pequenas;

IV. Análise e sistematização dos dados. Elaboração e confecção de tabelas, gráficos e mapas que possibilitem uma melhor visualização dos dados tabulados. Avaliação das informações coletadas, interpretação e estabelecimento de comparações a partir do levantamento teórico sobre o tema. Elaboração de conclusões e síntese acerca do referencial empírico em estudo.

O uso de instrumentos serve para auxiliar nas atividades práticas e teóricas: os softwares (para representação cartográfica e confecção de tabelas) e hardwares (scanner, microcomputador). 
Para o desenvolvimento do estudo houve possibilidade de trabalhar, prioritariamente, com dados secundários. Isto é um diferencial para a região, que por ser um centro de atrativo econômico e possuir importantes centros de pesquisa, torna-se objeto de estudo de diferentes natureza. Como resultado tem-se um conjunto expressivo de informações sobre a região como tudo e seus municípios em particular. Todavia, embora tenha sobressaído um exercício-analítico com base em dados secundários, a análise empírica foi fundamental. Conhecer a realidade previamente, e fazer sua releitura através de um conjunto de dados sistematizados, permitiu identificar as aproximações e divergências existentes entre a realidade e os conceitos científicos.

Como cabe ao pesquisador-cientista não apenas observar os fatos, mas também interpretálos, o desenvolvimento de uma metodologia sistematizada é um meio de atingir os melhores resultados na interpretação das cidades pequenas, ante o conjunto regional. Portanto, o ponto de partida para se analisar as cidades pequenas é considerá-las como parte de um processo mais amplo da economia e da urbanização, inserida em uma estrutura dinâmica: a rede urbana. Isto significa que foi adotado um recorte mais amplo (a região) e como integrantes menores as cidades pequenas e seu conjunto municipal. De tal modo, foi possível chegar nas seis características que serão expostas a partir de agora.

\section{As cidades pequenas entre as novas e as velhas interações com o rural}

Parcela significativa das cidades pequenas sempre teve uma maior ligação com os valores rurais e com as formas de produção agrícola. Por conta disto, a relação cidade-campo e a discussão entre o urbano e o rural estão entre os temas mais apreciados pelos geógrafos que estudam cidades pequenas (BERNARDELLI, 2004; LOPES, 2005; QUEIROZ, 2008; SILVA, 2010; E FABRINI, 2009). O tênue limiar entre a cidade e o campo está presente tanto na dependência da atividade produtiva que tem peso expressivo no setor primário, quanto na paisagem urbana, na morfologia das cidades e no modo de vida da população.

No caso da região campineira, o setor primário, ainda, assume papel importante para as cidades de Artur Nogueira, Santo Antônio de Posse, Engenheiro Coelho e Holambra, porém com particularidades. Isto pode ser comprovado, de um lado, pela participação do setor na composição do PIB municipal, como comprovam os dados registrados em 2009: Holambra (22\%), Engenheiro Coelho (10\%), Santo Antônio de Posse (6\%) e Artur Nogueira (6\%). De 
outro, o setor agropecuário tem representado uma importante fonte de empregos, como revela os dados da Fundação SEADE, para o ano de 2010: Holambra (47\%), Santo Antônio de Posse (18\%), Engenheiro Coelho (12\%) e Artur Nogueira (9\%).

As diferenciações, entretanto, são significativas entre os municípios. Vale exemplificar com os casos de Holambra e Engenheiro Coelho. Na primeira, a especificidade do campo sustenta a existência de um setor agroindustrial, de caráter altamente especializado (produção de flores e plantas ornamentais) e que abriga parcela significativa de trabalhadores. $\mathrm{Na}$ segunda, o setor agropecuário ainda define a tipologia municipal, assumindo papel importante para a economia do município, com extensas áreas destinadas a produção de cana de açúcar, citros e milho.

Holambra merece destaque pelo caráter especializado que assume esta atividade produtiva. O ponto forte é a produtividade e a qualidade no segmento da floricultura. Assim, se a base de sua economia é a agropecuária, o setor industrial e o terciário (especialmente o turismo) se favorecem desta especificidade e assumem características particulares para o município.

Embora a atividade agropecuária tenha significado importante para a caracterização das cidades pequenas envolvidas no processo de metropolização, não atinge a mesma relevância econômica verificada nos centros urbanos localizados em regiões tipicamente agrícolas.

Um aspecto que ganha destaque maior numa área metropolitana é a clareza com que, do ponto de vista espacial, o rural só pode ser entendido como um "continuum" do urbano, utilizando a concepção de Graziano da Silva (1997). Neste contexto se intensifica o número de atividades não propriamente agrícolas no meio rural e uma nova opção de áreas de moradia para os segmentos mais abastados, como é o caso dos loteamentos de chácaras e dos condomínios fechados.

O chamado processo de rurbanização ${ }^{3}$ é percebido na região de Campinas, com novos conteúdos que são atribuídos ao espaço rural, especialmente no que condiz com a extensão de novas formas espaciais para a habitação. Os loteamentos de chácara, localizados em

3. Tanto em Freyre (1982) quanto em Graziano da Silva (1997), o termo rurbanização pode ser interpretado como processo de extensão das atividades e estruturas urbanas em espaços rurais. 
áreas de menor densidade, representam o maior exemplo disto. Eles são diversos e estão presentes em todos os municípios, tais como: Condomínio Reserva da Mata, Haras e Fazenda Larissa (Monte Mor); Condomínio Fazenda Duas Marias (Jaguariúna); Portal dos Manacas, (Artur Nogueira); Condomínio Náutico Represa (Pedreira); Esparta Park (Engenheiro Coelho); Loteamento Fechado Flor D’Aldeia (Holambra).

Estes empreendimentos representam um novo conteúdo mercadológico, voltado para os segmentos mais abastados. Se, por um lado, criam espaços diferenciados, separado do núcleo central da cidade, de outro, reverbera numa "mudança de uso da terra rural que passam a ser valorizadas quando se trata da moradia" (PIRES, 2004).

No caso de uma região metropolitana o fenômeno é favorecido pela proximidade territorial existente entre os municípios e pela extensa malha viária que amplia as possibilidades de deslocamento. Logo, não são espaços criados para atender, particularmente, a população local de cada município, mas são pensadas para o conjunto metropolitano.

\section{As cidades pequenas industriais}

No que diz respeito a atividade produtiva o setor secundário tem um significado relevante, tanto para a composição do PIB quanto para os empregos. Diferentemente de cidades pequenas localizadas distantes de centros economicamente dinâmicos, na região metropolitana existe uma série de condições e determinantes que beneficia o desenvolvimento da atividade industrial.

Em síntese, o processo de industrialização do conjunto regional foi favorecido pela "extensão do território produtivo" de Campinas para os municípios próximos ou contíguos, como destacou Slingard-Sampaio (2009). Ainda de acordo com esta autora, uma série de fatores contribuiu para que isto se concretizasse: a excelente rede rodoviária (que realiza tanto a interligação municipal quanto a regional), concessões e estímulos oferecidos por municípios ("guerra fiscal”) e o processo espacial de conurbação.

Não por acaso, a participação do setor industrial, no PIB, tem expressão maior do que a encontrada em cidades pequenas de áreas não metropolitanas. Atinge a marca de $55 \%$ em Monte Mor, 40\% em Jaguariúna, 36\% em Engenheiro Coelho, 33\% em Artur Nogueira e 31\% em Pedreira, segundo dados do IBGE para 2009. Da mesma forma, o percentual de pessoas 
ocupadas na atividade industrial é elevado: Pedreira (56\%), Monte Mor (43\%), Artur Nogueira (36\%).

As atividades, entretanto, são variadas com complexidades diferenciadas. Para exemplificar e demonstrar o grau de complexidade é válido realizar um exercício analítico sobre três cidades: Jaguariúna, Monte Mor e Pedreira, o que contribui para refletir, inclusive, acerca do papel seletivo e setorial das empresas.

Jaguariúna é bem servida em termos de malha rodoviária, o que facilita a conexão com outros centros e uma integração direta à Campinas, Ihe garantindo uma localização estratégica com facilidades ao acesso, transporte e logística. Isto permitiu a consolidação de um parque industrial de estrutura complexa e de alta tecnologia. Destaca-se a atividade industrial em torno de material eletrônico e equipamentos de comunicações, como é o caso da MOTOROLA. Ademais, tem grande expressão sua participação nos segmentos de bebidas, com a instalação da AmBev (Companhia de Bebidas das Américas) e indústrias dos setores alimentícios e farmacêuticos.

O caso de Monte Mor é diferenciado. Sua malha urbana já se encontra em processo de conurbação. $O$ crescimento da cidade tem ocorrido nas margens da rodovia que liga a cidade à Hortolândia e Campinas. Isto foi influenciado, principalmente, pela localização de empresas às margens da rodovia, como são os casos da Tetra Pak, a Haver e Boecker, por exemplo. Em decorrência disto bairros residenciais, também, passaram a se estruturar nas proximidades das rodovias, evidenciando um crescimento espacial que teve como preocupação maior as questões com a fluidez, a proximidade com as atividades produtivas e a proximidade com a cidade central da região.

É notável, portanto, o controle da produção do espaço e a dependência econômica que se estabelece em relação ao capital. Tanto o desenvolvimento da atividade produtiva, quanto a reprodução dos espaços de moradia (seja para os segmentos trabalhadores ou para a população mais abastada) são determinadas por interesses mercadológicos. Numa região metropolitana isto favorece a atuação da especulação imobiliária sobre a terra, especialmente, a urbana.

Do ponto de vista da atividade industrial, Silva Neto (2008), expõe os riscos de uma atividade altamente dependente da dinâmica econômica exógena, uma vez que a localização da 
atividade produtiva industrial é sempre representativa de um determinado momento, de acordo com interesses dos agentes econômicos. De tal modo, a transferência destas empresas para outros lugares em busca de vantagens competitivas pode reverberar em consequências drásticas a estas cidades, tanto do ponto de vista econômico quanto tributário e social.

Diferentemente, Pedreira, um centro especializado, cuja economia está voltada para um setor industrial específico: a produção cerâmica e porcelana. Dele, também, deriva o setor comercial. Juntos, são responsáveis pela quase totalidade do PIB municipal e por grande contingente de postos de empregos. O fato de estar inserida numa região metropolitana beneficia sua atividade produtiva. No entanto, por possuir um caráter industrial que se desenvolveu, historicamente, graças à localização geográfica e condições naturais locais do município, a dependência ao grande capital e aos atores exógenos é menor que nos outros casos. Ademais, conta, ainda, com produtos de alumínio, ferro, madeira, gesso, vidro, plástico e resina.

\section{As cidades-dormitório}

O processo de metropolização de Campinas, enquanto fenômeno geográfico envolve níveis diferenciados de complexidade, devido as características particulares das municipalidades que estão inseridas na região metropolitana, reconhecida institucionalmente. Todavia, o que há em comum é que todos possuem um dinamismo ligado à Campinas, pois estão inseridas dentro de um mesmo processo, contudo, em estágios e situações diferenciados.

Aspectos particulares da dinâmica demográfica, das relações socioeconômicas e de suas interações na região metropolitana permitem pensar a composição de centros urbanos que podem ser definido como "cidade-dormitório". A ideia não é reduzir a função destas cidades ao caráter residencial, mas destacar que, conforme Corrêa (2011), trata-se de cidades pequenas localizadas a uma distância próxima que viabilizam deslocamentos pendulares daqueles que ali vivem, mas trabalham numa cidade maior.

Sendo assim, não implica que sua única ou principal função seja a residencial, como advertiu Ojima et al. (2010). Tampouco significa ou tem ligações diretas com formas de exclusão social ou de segregação dentro da região. Eles podem ocultar outros indicadores que possibilitem identificar o caráter destas áreas urbanas. No caso da região campineira, por 
exemplo, Valinhos e Vinhedo foram consideradas, na análise de Miglioranza e Cunha (2006), "municípios-dormitório de luxo". Isto se deve ao caráter assumido pela expansão metropolitana e de dispersão da população. Os dois municípios são marcados pela proliferação de condomínios residenciais, loteamentos fechados e bolsões de segurança, voltados para os segmentos mais abastados da região.

Em contrapartida, pode-se citar os casos de Hortolândia e Sumaré como municípiosdormitório com grande concentração de população de baixa renda. Sendo que, neste grupo, é possível incluir também Monte Mor, que apresenta altas taxas de deslocamentos pendulares.

Os deslocamentos pendulares constituem um processo entre a organização da população e da disposição das atividades no espaço metropolitano. Estes dados podem ser espacializados e permitem compreender a extensão dos processos aglomerativos e das centralidades que se confirmam no conjunto regional.

O melhor exemplo disto é o percentual de pessoas que não trabalha no município onde reside. Para o caso das cidades pequenas vale destacar que, Artur Nogueira e Monte Mor registraram, de acordo com o censo de 2010 , respectivamente, $31,1 \%$ e $31,7 \%$ de população ocupada fora do município de residência. Enquanto que Holambra, Engenheiro Coelho e Santo Antônio de Posse apresentam, respectivamente, percentuais com cerca de $17 \%$, 20\% e $27 \%$. Em contrapartida, Jaguariúna, que é um centro polarizador, possui menores índices (abaixo de 15\%).

Monte Mor possui características diferenciadas por sua situação geográfica metropolitana. Diferentemente das outras cidades pequenas da região, é a mais próxima da cidade central e cujo processo espacial de conurbação já está em curso. Acrescenta-se, também, a intensidade de fluxos permitidos pelas linhas de ônibus intra-metropolitanos. De acordo com a Empresa Metropolitana de Transportes Urbanos de São Paulo (EMTU), Monte Mor é a cidade que possui maior ligação com Campinas. São 156 linhas integrando as duas cidades. Para efeito de comparação, as outras cidades com maior número de linhas de ônibus intrametropolitano são Jaguariúna, com 63, e Artur Nogueira, com 23. 
Portanto, tanto a proximidade espacial quanto o maior acesso por meio de vias rápidas contribuem para determinar o local de trabalho e o de residência para parcela da população. Ao mesmo tempo em que criam significados diferenciados para os espaços urbanos.

\section{As cidades pequenas e as relações mais próximas de sociabilidade}

Quando se pensa em cidade pequena, corriqueiramente, remete-se a ideia de lugar repleto de tranquilidade, pacato, bucólico, de pessoas simples e de vidas descomplicadas. 0 tamanho reduzido, tanto em termos populacional quanto territorial, favoreceriam as relações mais próximas de sociabilidade entre as pessoas, graças ao convívio dos espaços em comum: a igreja, a praça, o centro, entre outros. Ademais, as características destas cidades permitiria uma maior proximidade entre a população e seus governantes, criando outras relações na governabilidade local.

Em geral e de modo diferenciado as questões de proximidade ainda se sobressaem em cidades pequenas. A tal ponto que é colocado por Soares e Melo (2010), como um dos elementos que caracterizam as cidades pequenas e seu estudo na Geografia. Estas relações envolvem práticas socioespaciais que ajudam a caracterizar, geograficamente, estes espaços urbanos.

A questão da proximidade envolve, ainda, referenciais para "a localização de endereços nas cidades, nas atividades comerciais e nas relações políticas" (SOARES; MELO, 2010). Este aspecto abrange a esfera econômica, pois além de dar garantia de sociabilidade, são sentidas, também, no quadro de empregos. Seja pela existência de trabalhadores formais e informais nos serviços públicos e administrativos das prefeituras, seja pelo comércio local, em especial, as feiras livres, que "se destaca pela sua centralidade e por abrigar muitos pequenos agricultores, artesãos e desempregados" (ASSIS, ARAUJO, 2009).

Para o caso da região metropolitana, entretanto, novos contornos envolvem a proximidade e sociabilidade entre as pessoas. Inicialmente, desponta a questão da centralidade e das tentativas de integração territorial, no âmbito regional. A expansão da malha urbana assume um aspecto de crescimento pautado no espraiamento em direção à cidade central. Monte Mor é o melhor exemplo disto. Nesta cidade, já é possível identificar a consolidação de processos espaciais de conurbação. Porém, com se trata de uma metropolização incompleta, no sentido de seu aspecto institucional se sobressair em relação a dimensão geográfica, os 
espaços conurbados são, contraditoriamente, marcados por repletos vazios urbanos e metropolitanos.

Integrar-se à cidade central tornou-se importante, tanto por causa do desempenho das atividades produtivas e dos empregos quanto para consumir aquilo que não é característico dos pequenos centros urbanos, como shopping centers, hipermercados, teatros, casas de espetáculos, entre outros. Ademais, a proximidade espacial regional propiciou a geração de novas formas espaciais e novas relações socioespaciais, que tem desdobramentos nas práticas locacionais. Ressalte-se, dois exemplos.

O primeiro diz respeito aos espaços da moradia. Como mencionado anteriormente, a proliferação de loteamentos horizontais fechados e de loteamentos de chácaras revelam uma nova concepção de morar e viver. Consequentemente, resultam em formas de autosegregação espacial. Tratam-se de empreendimentos que produzem espaços diferenciados: murados, vigiados e com acesso controlado; voltados para um segmento social específico.

O segundo exemplo mencionado refere-se aos deslocamentos pendulares, característico de áreas metropolitanas, como foi mencionado anteriormente. O dinamismo econômico regional e a proximidade entre as cidades permitem que parcela significativa da população trabalhe fora do município de residência.

Não morar no município em que reside pode ser explicado, grosso modo, por dois motivos principais. O primeiro, são as escolhas por espaços auto-segregados, nos quais as áreas para construção da moradia são maiores e possuem outras amenidades ambientais. O segundo, que engloba a população trabalhadora, é o fato da terra urbana em cidades pequenas ser mais barata que nas cidades maiores, especialmente, no núcleo metropolitano. O que vale destacar é que estas formas de morar e vivenciar o espaço metropolitano dão outros contornos aos aspectos de sociabilidade para estas cidades, tornando-os mais restritos. As relações de pessoalidade e de convívio em espaços em comum, não ocorre da mesma forma e com a mesma intensidade que em cidades pequenas localizadas em áreas nãometropolitanas.

Adiciona-se, ainda, a escalada da violência nestas cidades. De fato, o medo e a insegurança já fazem parte destes espaços que perderam a característica de serem espaços de tranquilidade. Se, não raramente, são noticiados casos de roubos coletivos a bancos, com 
explosões de caixas eletrônicos, deve considerar, ainda, aquelas cidades que atualmente abrigam presídios gerando, dentre outros, problemas de segurança. Soriano (2007), procurou exemplificar isto, desenvolvendo um estudo sobre violência, criminalidade e os espaços de medo em cidades pequenas, tendo como referencial empírico o município de Itirapina, no interior do estado de São Paulo.

Para o caso específico das cidades pequenas da Região Metropolitana de Campinas, de modo diferenciado, é notável aquilo que pode ser definido como difusão espacial da criminalidade. Um exemplo é o Mapa da Violência, elaborado por Waiselfisz (2011), com base na taxa de homicídios para o grupo de 100 mil habitantes. O resultado deste levantamento revelou para 2010, que os municípios que possuíam as taxas mais elevadas, na região, eram Monte Mor e Santo Antônio de Posse (acima de 26\%). Fica evidente, portanto, que o dinamismo regional não propicia apenas um desenvolvimento no âmbito da economia, mas os ônus também são divididos, quiçá de modo mais contundente que os bônus sociais do chamado desenvolvimento metropolitano.

Não é ao crescimento metropolitano ou desenvolvimento econômico em si que estão ligados ao aumento da violência, mas sim a forma como eles ocorrem. O modo como se dão os processos de reprodução do espaço e da organização das atividades econômicas, em suas múltiplas escalas, geram espaços diferenciados. Então, as mudanças na dinâmica e nas características demográficas, também, assumem relevância por apresentar repercussões espaciais. Sendo que o cerne desta diferenciação é o social e o econômico.

A proximidade espacial, portanto, possui atributos que criam novas formas espaciais com conteúdos específicos que caracterizam a espacialização da população. Nas cidades pequenas de uma região metropolitana estes aspectos assumem elevado grau de complexidade. Afinal, de um lado, tem-se um ressecamento das relações sociais, enquanto, de outro, o modo de vida possui características interioranas, marcadas por relações de maior pessoalidade e sociabilidade. Exemplos são: o uso das praças pelos jovens; a rua não somente como espaço de passagem, mas de diálogos; o reconhecimento das pessoas pelo nome ou sobrenome; as relações de vizinhança; entre outros.

O poder local nas cidades pequenas de uma área metropolitana 
Os interesses em comum para a integração da organização, planejamento e execução de funções públicas é a finalidade principal da criação institucional de uma região metropolitana. Enquanto fenômeno geográfico, a "metropolização consiste em um processo de integração de território a partir da cidade-núcleo, configurando um território ampliado" (IPEA, 2011). Porém, tanto a integração espacial quanto o aspecto da governança territorial devem ser avaliados, especialmente no que tange a sua abrangência de participação às cidades pequenas.

Na Região Metropolitana de Campinas pode-se observar a composição de dois grupos de cidades: um integrado, articulado e com interações espaciais, econômicas e populacionais claramente estabelecidas; outro, composto por cidades menores, distantes, descontínuas e fragmentadas da integração territorial. Isto representa verdadeiros desafios a consolidação da região metropolitana, especialmente, no que diz respeito a governabilidade territorial, tanto na esfera municipal, quanto regional.

Para o caso da região em estudo, existem ferramentas legais para o processo organizacionalinstitucional de construção de estratégias para as ações coletivas e formulação de políticas públicas de desenvolvimento local/regional. São os casos da EMPLASA (Empresa Paulista de Planejamento Metropolitano SA) e da AGEMCAMP (Agência Metropolitana de Campinas), diretamente vinculadas à Secretaria de Economia e Planejamento do Estado de São Paulo.

A EMPLASA é um órgão institucional que engloba o planejamento, a implementação de projetos, sua viabilização e articulação, visando a organização do território da Macrometrópole Paulista ${ }^{4}$. Isto significa que tem atuação numa escala mais ampla, cujos projetos e estudos, têm ocorrido com foco em temáticas diversas (mobilidade pendular na Macrometrópole Paulista; finanças públicas e capacidade de investimentos; sistema de informações geográficas para o planejamento metropolitano; entre outros).

4. O governo do estado de São Paulo tem a proposta de criação de uma “Macrometrópole Paulista” que abrangeria as quatro regiões metropolitanas paulistas (São Paulo; Campinas; Baixada Santista; e Vale do Paraíba e Litoral Norte); as aglomerações urbanas de Jundiaí, Piracicaba e Sorocaba; além da Microrregião Bragantina e a de São Roque. Não se trata de uma região instituída formalmente, mas de "um novo fato urbano e/ou de um fenômeno que se materializa como nova escala de urbanização, estruturando, no estado de São Paulo, um território funcionalmente integrado" (ESTADO DE PAULO, 2011). 
A AGEMCAMP (Agência Metropolitana de Campinas) tem por finalidade assegurar a execução de planos, programas e projetos relacionados às funções públicas de interesse comum na região metropolitana. Sua abrangência vai desde a fiscalização das execuções das leis e planos de interesse comum, até a manutenção de estruturas técnicas e administrativas.

São pensadas para contemplar todos os municípios da região metropolitana, de todos os portes territoriais e populacionais. Afinal, objetiva, de um lado a consolidação da região metropolitana e, de outro, o desenvolvimento regional. Como o alcance das chamadas funções públicas de interesses em comum é vasto, envolvendo questões territoriais, ambientais, econômicas, sociais, além de questões institucionais e urbanísticas, são criadas Câmaras Temáticas que visam contemplar cada uma delas.

Entretanto, existem descompassos perceptíveis na execução dos planos. Isto pode ser notado na proposta da deliberação das Câmaras Temáticas, que não abrangem todas as cidades pequenas, como está registrado na Tabela 2.

\begin{tabular}{|c|c|c|c|c|c|c|c|}
\hline CÂMARA TEMÁTICA & $\frac{\text { 롱 }}{\text { 를 }}$ & 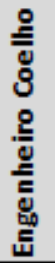 & 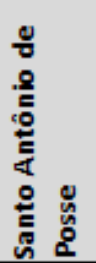 & $\begin{array}{l}\text { 昱 } \\
\text { 量 } \\
\text { 总 } \\
\text { 点 }\end{array}$ & 를 & 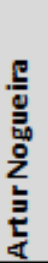 & $\begin{array}{l}\frac{1}{2} \\
\frac{0}{2} \\
\frac{0}{2} \\
\frac{0}{2}\end{array}$ \\
\hline Transportes & & & & $\mathrm{X}$ & & & \\
\hline Cultura & $\mathrm{x}$ & & & $\mathrm{x}$ & $\mathrm{x}$ & & \\
\hline Agricultura & $\mathrm{X}$ & $\mathrm{X}$ & $\mathrm{X}$ & $\mathrm{X}$ & $\mathrm{X}$ & $\mathrm{X}$ & $\mathrm{X}$ \\
\hline Saúde & & & & $\mathrm{X}$ & & $\mathrm{X}$ & $\mathrm{X}$ \\
\hline Educação & & & & $\mathrm{X}$ & & $\mathrm{X}$ & \\
\hline Atendimento Social & & & & $\mathrm{x}$ & $\mathrm{x}$ & $\mathrm{x}$ & $\mathrm{X}$ \\
\hline Saneamento & $\mathrm{x}$ & & & $\mathrm{X}$ & $\mathrm{X}$ & & \\
\hline Desenvolvimento econômico & & & & $\mathrm{x}$ & & & \\
\hline Transporte e sistema viário regional & $\mathrm{x}$ & & & $\mathrm{x}$ & $\mathrm{x}$ & & $\mathrm{X}$ \\
\hline Planejamento e uso do solo & $\mathrm{x}$ & & & $\mathrm{x}$ & & $\mathrm{X}$ & \\
\hline Mein amhiente & $x$ & & & $x$ & & & \\
\hline
\end{tabular}

Tabela 2: Composição das Câmaras Temáticas nos municípios estudados da Região Metropolitana de Campinas. Fonte: AGEMCAMP / Org.: Orlando Moreira Junior (2014).

Dentre as cidades pequenas, somente Jaguariúna participa de todas. Em contrapartida Engenheiro Coelho e Santo Antônio de Posse tem uma participação mais reduzida. Este cenário auxilia na reflexão acerca da integração efetiva da área metropolitana. Afinal, apesar de compor a região em seu caráter institucional, na prática o conjunto de cidades não é pensado como totalidade. 
A Câmara Temática de Agricultura é a única composta pelos sete municípios com população inferior a 50 mil habitantes. O espaço rural, ainda, tem um significado para as cidades pequenas, especialmente, no que tange o desenvolvimento das atividades produtivas. Isto justificaria a inserção de todos nesta Câmara Temática, contribuindo para conferir às cidades pequenas, no âmbito regional, uma característica particular.

Todavia, apesar da AGEMCAMP promover e incentivar as interações, o problema é que as ações parecem ter ficado, somente, no plano das ideias e do discurso. São elaborados diagnósticos, planos, relatórios, propostas e seminários entre as prefeituras, mas, como se tudo fizesse parte de um roteiro, institucionalmente, imposto. Correspondem a ações normativas ou reguladoras que reúnem as principais ideias, fundamentos e orientações que servem mais para justificar a metropolização institucional, do que adotar uma postura transformadora para os municípios que a compõe.

Os impasses e as limitações na tomada de decisões em comum são sentidos, também, na gestão urbana de cada municipalidade. A preocupação com o aspecto metropolitano é explicitado nos Planos Diretores dos municípios. Tanto no plano de Holambra quanto no de Pedreira, está firmado como objetivo a consolidação de instrumentos para uma gestão metropolitana. No Plano Diretor de Jaguariúna, por sua vez, além da preocupação com a integração regional, via planejamento, há ainda, preocupação com medidas para fortalecer a posição do município como polo da região. O plano de Artur Nogueira visa fundar um centro metropolitano de convenções e exposições. Enquanto, em Monte Mor, a preocupação remete apenas a necessidade de melhorar os acessos rodoviários aos municípios vizinhos.

Isto significa que a tentativa de articulação e integração regional são preocupações dos governos locais. Porém, isto envolve mais as dimensões econômicas e políticas do que sociais. Dentre as sete cidades analisadas, Jaguariúna e Monte Mor, por motivações variadas, foram as que mais se envolveram no processo de metropolização. Contudo, a segunda expõe sérios problemas socioespaciais, denunciando que dar a cidade o "título" de metropolitana nada altera em termos de desenvolvimento social. Pelo contrário, pode gerar cenários de elevada dependência, tanto do sistema urbano-regional quanto do capital produtivo, bem como expor a capacidade de ação dos governos locais. 


\section{RESULTADOS E DISCUSSÃO}

As seis características elencadas propiciam análise da diferenciação do comportamento das dimensões econômicas e sociais ante o processo de institucionalização da Região Metropolitana de Campinas. A concentração e polarização no núcleo metropolitano composto pela cidade principal e algumas cidades de porte médio ainda é um fato evidente no cenário regional.

O estudo geográfico das interações entre dinâmica demográfica e questões socioeconômicas revela aspectos particulares na leitura e interpretação dos papéis desempenhados por cidades pequenas, sendo, portanto, importante considerá-las sempre diante do contexto regional. Cidades pequenas localizadas em áreas economicamente dinâmicas (como é o caso da Região Metropolitana de Campinas) podem apresentar dinâmicas e interações que diferenciam suas atividades produtivas, o perfil da população e o significado dos papéis que tendem a assumir no contexto regional.

As cidades pequenas só podem ser compreendidas, portanto, a partir do sistema urbanoregional, no qual mudanças na organização socioespacial da região tendem a ser decisivas para a reestruturação urbana, redefinindo a divisão territorial do trabalho e a distribuição populacional no cenário metropolitano como um todo. Em razão da função principal que cada cidade assume, pode-se aludir ao papel que cada uma delas cumpre na divisão territorial do trabalho.

O fato de estarem localizadas numa região metropolitana, traz para as cidades pequenas algumas particularidades que não são encontradas naquelas situadas distantes de grandes centros econômicos. Um exemplo, é o maior significado adquirido pelo setor secundário. Isto ajuda a explicar a representatividade, a nível estadual, assumida por Jaguariúna, que, setorialmente, integra o complexo de alta tecnologia em informática e telecomunicações, numa leitura dos Complexos Produtivos Setoriais, efetuado por Selingard-Sampaio (2009).

Ao mesmo tempo, é evidente que as cidades que mantém maiores relações com o campo são as pequenas, como são os casos de Holambra, Engenheiro Coelho, Santo Antônio de Posse e Artur Nogueira. Entretanto, a relação urbano-rural ganha novas complexidades, que são expressas pela existência de atividades modernas, a atuação de atores hegemônicos ou outros aspectos típicos do circuito superior da economia urbana, influenciando a 
organização do espaço urbano e econômico das cidades pequenas. Diante disto, importante reforçar as especificidades existentes nas cidades agroindustriais ou agroterciárias.

A dependência do sistema urbano-regional desponta como elemento central na análise das cidades pequenas numa região metropolitana. No caso do referencial empírico deste estudo, tanto as relações envolvendo a atividade produtiva quanto as relações ligadas a dinâmica socioespacial evidenciam isto. As cidades-dormitórios, os movimentos pendulares, as cidades com caráter industrial - de estrutura simples ou complexa -, as determinantes que propiciam diversas interações espaciais, as práticas socioespaciais da população, a gestão integrada dos interesses em comum, entre outros, simbolizam elementos que dão singularidade a estas cidades pequenas que ora atribuem a elas características tipicamente metropolitanas, ora as negam.

É claro que por estar incluída, institucionalmente, numa região metropolitana contribui para o surgimento ou permanências de fragmentos modernos e globalizados, que muitas vezes coexistem com conteúdos históricos (seja nas formas arquitetônicas, nos traçados das vias ou no modo de vida) e manifestações de simplicidade do dia a dia (a feira livre, os festejos religiosos ou típicos, entre outros). Estes são traços marcantes que indicam diferenciações na interpretação dos significados destas realidades urbanas.

Devido a multiplicidade e complexidade de fatores que envolvem estes espaços, os papéis que elas assumem são difíceis de apreender, devido os diferentes elementos que os compõem. Em sua totalidade assumem significados diferenciados que só podem ser compreendidos no conjunto regional. Desta forma, os aspectos que foram elencados contribuem para olhar esta tipologia de cidades para além de suas funções administrativas, políticas ou econômicas, englobando os aspectos socioespaciais delas decorrentes e considerando a dinamicidade e possibilidades de interações permitidas pelo contexto regional-metropolitano. Isto não leva, necessariamente, à perda de papéis urbanos ou à estagnação econômica de cidades menores, mas atribui particularidades que contribuem para a organização do sistema urbano-regional.

Ademais, há, nitidamente, um rompimento com a ideia de rede urbana tradicional, uma vez que as cidades pequenas desempenam papéis que não necessitam de intermediação nas relações que se estabelecem diretamente com a cidade central da região metropolitana. Isto 
ajuda a explicar as particularidades que envolvem sua dinâmica territorial diferenciada em comparação com cidades pequenas localizadas distantes de grandes centros econômicos.

\section{CONSIDERAÇÕES FINAIS}

O fato de estarem inseridas numa área metropolitana, principalmente, quando se trata de uma região economicamente dinâmica, concebe às cidades pequenas novas características populacionais, funcionais e espaciais. Estas lógicas particulares introduzem condições e dinâmicas diferenciadas a elas que, juntamente, com lógicas gerais de produção e organização do espaço, permitem estabelecer comparações com cidades localizadas em áreas não-metropolitanas.

O objetivo deste trabalho foi expor alguns aspectos que estão ligados as cidades pequenas ante a inserção do mundo globalizado; da dependência que se cria entre o sistema urbanoregional; o entorno rural, as ruralidades e as urbanidades; os aspectos de sociabilidade entre a população, entre outros.

Estes aspectos, além de assumir outras formas e significados, são responsáveis para definir os papéis urbanos ante a divisão territorial do trabalho no âmbito regional. Sem a pretensão de generalizar, ficou claro que cidades pequenas, ante o cenário metropolitano, possuem atributos econômicos, populacionais e políticos que tem desdobramentos no espaço, mesmo quando a metropolização possui um caráter mais institucional do que geográfico. A centralidade e a influência exercida pela cidade central, bem como a proximidade, mesmo quando criada pelas possibilidades de deslocamento, tanto pela conurbação quanto pelas integrações viárias, evidenciam interações singulares para este contexto regional, o que deve ser considerado na compreensão destas realidades urbanas.

\section{BIBLIOGRAFIA}

ALMEIDA, A. P. Produção industrial em pequenas cidades e reinserções na rede urbana: o caso de Assai-PRhttp://www.agb.org.br/evento/download.php?idTrabalho=147. In: XVI Encontro Nacional de Geógrafos. Porto Alegre, Anais XVI ENG, 2010. CD Rom.

ASSIS, L. F. de; ARAÚJO, F. F. A centralidade do comércio na cidade pequena nordestina: o caso da feira livre de Varjota (Ceará/Brasil). Scripta Nova. Revista Electrónica de Geografía y Ciencias Sociales. Barcelona: Universidad de Barcelona, 1 de julho de 2009, v. XIII, n. 29. 
BERNARDELLI, M. L. F. H. Pequenas cidades na região de Catanduva-SP: papéis urbanos, reprodução social e produção de moradias. 2004. 347f. Tese (Doutorado em Geografia) - FCT, UNESP, Presidente Prudente.

Os papéis urbanos na região de Catanduva: relações entre a produção de moradia e o trabalho volante. Scripta Nova. Revista eletrônica de geografia y ciencias sociales. Barcelona: Universidad de Barcelona, ago. 2003, v. VII, n. 146(081).

BERNARDELLI, M. L. F. H.; MATUSHIMA, M. K. Pequenas cidades no vale do Ivinhema-MS: papéis urbanos, reprodução social e produção de moradias. In: XV Encontro Nacional de Geógrafos. São Paulo, Anais XV ENG, 2008. CD Rom.

CAPEL, H. Las pequeñas ciudades en la urbanización generalizada y ante la crisis global. Investigaciones Geográficas, México, n. 70, diciembro, 2009, p. 7-32.

CHAGAS, S. E. A. Pequenas cidades e produção territorial: elementos para a discussão geográficahttp://www.agb.org.br/evento/download.php?idTrabalho=147. In: XVI Encontro Nacional de Geógrafos. Porto Alegre, Anais XVI ENG, 2010. CD Rom.

CASARIL, C. C. Pequenas cidades ou cidades locais? Por uma perspectiva teórico-metodológica atualhttp://www.agb.org.br/evento/download.php?idTrabalho=147. In: XVI Encontro Nacional de Geógrafos. Porto Alegre, Anais XVI ENG, 2010. CD Rom

CASTILHO, D.; CHAVEIRO, E. F. Cidade e dinâmica cultural: o contexto das cidades locais da microrregião Ceres, Goiás. In: XV Encontro Nacional de Geógrafos. São Paulo, Anais XV ENG, 2008. CD Rom.

CORRÊA, R. L. As pequenas cidades na confluência do urbano e do rural. GEOUSP. Revista da PósGraduação em Geografia, FFLCH/USP. São Paulo, n. 30, 2011, p. 05-12.

DAMIANI, A. L. Cidades médias e pequenas no processo de globalização: apontamentos bibliográficos. In: LEMOS, A. I. G.; ARROYO, M.; SILVEIRA, M. L. (Orgs.). América Latina: cidade, campo e turismo. São Paulo: CLACSO, Dez. 2006. p. 135-147.

ENDLICH, A. M. Gestão territorial compartilhada em espaços não-metropolitanos. Scripta Nova. Revista Electrónica de Geografía y Ciencias Sociales. Barcelona: Universidad de Barcelona, 1 de agosto de 2007, v. XI, n. 245 (64)

Pensando os papéis e significados das pequenas cidades do noroeste do Paraná. 2006. 507f. Tese (Doutorado em Geografia) - FCT, UNESP, Presidente Prudente.

Rede urbana, urbanidades e as pequenas cidades: ensaiando a discussãohttp://www.agb.org.br/evento/download.php?idTrabalho=147. In: XIII Encontro Nacional de Geógrafos. Porto Alegre, Anais XVI ENG, 2002. CD Rom.

ENGEL, A. S.; BESSA, K. C. F. O.; SOARES, B. R. A importância das cidades medias e locais na dinâmica urbana da bacia do rio Araguari-Minas Geraishttp://www.agb.org.br/evento/download.php?idTrabalho=147. In: XIII Encontro Nacional de Geógrafos. Porto Alegre, Anais XVI ENG, 2002. CD Rom.

ENGEL, A. S.; SOARES, B. R. A dinâmica urbana das pequenas cidades do cerrado mineiro e sua participação na rede urbana regional. In: VII Congresso Brasileiro de Geógrafos. Setenta anos da AGB: as transformações do espaço e a Geografia no século XXI. Goiânia, Anais VII Congresso Brasileiro de Geógrafos, 2004. CD Rom.

ESTADO DE SÃO PAULO. Secretaria de Planejamento e Desenvolvimento Regional. Secretaria de Desenvolvimento Metropolitano. Rede urbana e regionalização do Estado de São Paulo. São Paulo: EMPLASA, 2011.

FABRINI, J. E. A Reprodução contraditória do rural nas cidades pequenas. Terra Livre, v. 1, n. 32, jan/jun 2009, p. 137-152. 
GRAZIANO DA SILVA, J. O novo rural brasileiro. Nova Economia. Belo Horizonte, v. 7, n.1, mai. 1997, p. 43-81.

FREYRE, G. Rurbanização: Que é? Recife: Ed. Massangana/Fundação Joaquim Nabuco, 1982.

LEÃO, C. S.; SPOSITO, E. S. A dinâmica econômica em cidades pequenas: estudo de caso de Ouro Verde/SP. In: XIV Encontro Nacional de Geógrafos. Rio Branco, Anais XIV ENG, 2006. CD Rom.

LOPES, D. M. F. O conceito de urbano e as cidades de pequeno porte no semiárido baiano: Novo Triunfo, Santa Brígida e Sítio do Quinto. 2005. 175f. Dissertação (Mestrado em Geografia) Universidade Federal da Bahia, Salvador.

MELO, N. A. Pequenas cidades da microrregião geográfica de Catalão (GO): análises de seus conteúdos e considerações teórico-metodológicas. 2008. 527f. Tese (Doutorado em Geografia) UFU, Uberlândia.

MIGLIORANZA, E.; CUNHA, J. M. P. Valinhos: um novo padrão de cidade-dormitório? In: CUNHA, J. M. P. (org.) Novas metrópoles paulistas: população, vulnerabilidade e segregação. Campinas: NEPO/UNICAMP, 2006, p.539-560.

OJIMA, R.; MARANDOLA JR, E.; PEREIRA, R. H. M.; SILVA, R. B. O estigma de morar longe da cidade: repensando o consenso sobre as "cidades-dormitório" no Brasil. Cadernos Metrópole. São Paulo, v. 12, n.24, jul./dez. 2010, p. 395-415.

PINTO, L. A. V. Jaguapitã-PR: pequena cidade da rede urbana norte-paranaense especializada na produção industrial de mesas para bilhar. 2007. Dissertação (Mestrado em Geografia, Meio Ambiente e Desenvolvimento) - UEL, Londrina.

PIRES, A. "Novas" ruralidades, "velhas aspirações": reflexões sobre os caseiros de Vinhedo (SP). Estudos sociedade e agricultura. Rio de Janeiro, v. 12, n.2, 2004 p. 171-193.

QUEIROZ, M. A. Entre o rural e o urbano: cidades locais no CONSAD Paraná Centro-PR. In: XV Encontro Nacional de Geógrafos. São Paulo, Anais XV ENG, 2008. CD Rom.

SELINGARDI-SAMPAIO, S. Indústria e território em São Paulo: a estruturação do multicomplexo territorial industrial paulista. Campinas: ALÍNEA, 2009.

SILVA, G. K. N.. O uso do espaço pelas vaquejadas em cidades pequenas: o caso de Santo Antônio no Rio Grande do Norte. In: XVI Encontro Nacional de Geógrafos. Porto Alegre, Anais XVI ENG, 2010. CD Rom.

SILVA NETO, M. L.. Campinas em dois tempos: fato metropolitano e desigualdades da metropolização globalitária em São Paulo. In: SOUZA, M. A. A. (Org.) A metrópole e o futuro: refletindo sobre Campinas. Campinas: Instituto Territorial, 2008, p. 55-81.

SOARES, B. R.; MELO, N. A. Cidades médias e pequenas: reflexões sobre os desafios no estudo dessas realidades socioespaciais. In: LOPES, D. M. F.; HENRIQUE, W. (org.). Cidades médias e pequenas: teorias, conceitos e estudos de caso. Salvador: SEI, 2010, p. 229-250.

SORIANO, É. Os espaços de medo e os de castigo nas pequenas cidades do estado de São Paulo: o caso Itirapina. 2007. 157 f. Dissertação (Mestrado em Geografia) - IGCE, UNESP, Rio Claro.

SPOLAOR, S. Os papéis urbanos nas pequenas cidades da região da Quarta Colônia-RS. 2010. 192f. Dissertação (Mestrado em Geografia) - UFSM, Santa Maria.

WAISELFISZ, J. J. Mapa da violência 2012: os novos padrões da violência homicida no Brasil. São Paulo: Instituto Sangari, 2011.

\begin{tabular}{cc}
$\begin{array}{c}\text { Artigo submetido em } \\
\text { Artigo aceito em }\end{array} \quad$ 30/03/2015 \\
\hline
\end{tabular}

